\title{
A EFETIVIDADE DO DIREITO À MORADIA ADEQUADA A PARTIR DA SEGURANÇA NA POSSE NO DIREITO INTERNACIONAL E NO DIREITO BRASILEIRO
}

\author{
THE EFFECTIVENESS OF THE RIGHT TO ADEQUATE HOUSING FROM \\ POSSESSION SECURITY IN INTERNATIONAL LAW AND BRAZILIAN LAW
}

\author{
1 Juliano dos Santos Calixto \\ ${ }^{2}$ Maria Tereza Fonseca Dias
}

\section{RESUMO}

O direito à moradia, embora positivado na Constituição brasileira, já possuía bases normativas precedentes no âmbito internacional capazes de conferir-lhe efetividade. Este trabalho tem por escopo discutir se a efetividade do direito à moradia adequada está relacionada à distribuição de títulos individuais de propriedade em assentamentos informais ou se a segurança na posse pode ser garantida de forma apartada do direito de propriedade. Para responder este problema de pesquisa foi desenvolvida investigação de cunho dogmáticojurídico, mediante coleta de dados primários estatísticas, programas governamentais, legislações e tratados - e secundários, tais como bibliografia e estudos sobre o tema. A principal conclusão obtida é que o direito à moradia adequada, internacionalmente protegido, não deve estar necessariamente vinculado ao direito individual de propriedade, mas a diversos outros mecanismos de segurança na posse. Outras formas de exercício do domínio deveriam ser estabelecidos nas políticas habitacionais, tais como a propriedade coletiva, condomínios, alugueis subsidiados etc.

Palavras-chave: Direito à moradia adequada, Segurança na posse, Função social da propriedade urbana, Onu-habitat, Direito internacional, Constituição brasileira

\footnotetext{
${ }^{1}$ Doutorando em Direito pela Universidade Federal de Minas Gerais - UFMG, Minas Gerais (Brasil). Pesquisador pela Universidade Federal de Minas Gerais - UFMG, Minas Gerais (Brasil).

E-mail: juliano.direito@yahoo.com.br

${ }^{2}$ Doutora em Direito pela Universidade Federal de Minas Gerais - UFMG, Minas Gerais (Brasil). Professor de Direito Universidade Federal de Minas Gerais - UFMG, Minas Gerais (Brasil).

E-mail: mariaterezafdias@yahoo.com.br
} 


\begin{abstract}
The right to housing, although stated in Brazilian Constitution, already had previous international normative foundations able to give it effectiveness. The scope of this paper is discussing wether the effectiveness of the right to adequate housing is dependent on the distribution of individual property titles in informal settlements or if possession security can be guaranteed apart from property rights. To answer this research problem, a legal inquiry was developed, through primary data collection - statistics, government programs, statutes and treaties - and secondary data, such as literature and studies on the subject. The main conclusion drawn is that the right to adequate housing, protected internationally, should not necessarily be tied to individual property rights, but to many other possession security mechanisms. Other forms of exercising property rights should be established at housing policies, such as collective ownership, condominiums, subsidized rents etc.
\end{abstract}

Keywords: The right to adequate housing, Possession security, Social function of property, Onu-habitat, International law, Brazilian constitution 


\section{INTRODUÇÃO}

O direito à moradia, embora positivado no caput do art. $6^{\circ}$ da Constituição da República Federativa do Brasil de 1988 (CR/1988), como direito fundamental social, de natureza prestacional, após o advento da Emenda Constitucional no 64/2010, já possuía bases normativas precedentes no âmbito internacional capazes de conferir-lhe efetividade na ordem jurídica interna.

Em que pese esta efetividade ainda ser a questão central do exercício deste direito, sua inclusão na CR/1988 teve o condão não só de dar maior sustentação à formação de políticas públicas, como também passou a conferir aos cidadãos direitos públicos subjetivos, oponíveis ao Estado. No âmbito internacional, a discussão do direito à moradia mostra-se ainda deveras relevante se considerada a necessidade de densificar o conteúdo deste direito e estabelecer parâmetros mais objetivos para sua configuração e acesso. Trata-se, portanto, de definircritérios para a construção da noção de "Direito à moradia adequada", que vai além da noção de "quatro paredes e um teto" e do direito de propriedade, como será discutido adiante.

O presente trabalhopretende refletir e lançar luzes ao tema do Direito à moradia adequada a partir da noção da segurança na posse,no âmbito internacional,para compreender a sua aplicabilidade no contexto brasileiro.

Dados coletados pela ONU-Habitat, referentes a América Latina - e analisados adiante - que tratam dos problemas do déficit habitacional quantitativo e qualitativo bem como da relação entre a posse e a propriedade no exercício do direito à moradia adequada, leva a alguns questionamentos que serão tratados neste ensaio: o direito à moradia, internacionalmente protegido, deve estar vinculado ao direito de propriedade? A solução para a questão da efetividade do direito à moradia adequada está relacionada à regularização fundiária de assentamentos informais com a distribuição de títulos individuais de propriedade? A segurança da posse pode ser garantida de forma apartada do direito de propriedade? A noção de função social da propriedade, também positivada no ordenamento jurídico pátrio (art. $5^{\circ}$, XXIII, da CR/1988) seria suficiente para o exercício do direito à moradia adequada?

Para discutir estas indagações, foi desenvolvida investigação de cunho dogmáticojurídico, mediante coleta de dados primários - estatísticas, planos e programas governamentais nacionais e internacionais, legislações e tratados - e secundários, tais como bibliografia e estudos sobre o tema, analisando-os, a seguir, sob perspectiva qualitativa. 


\section{O DIREITO À MORADIA ADEQUADA NO ÂMBITO INTERNACIONAL E SUA APLICAÇÃO NA ORDEM JURÍDICA INTERNA}

O direito à moradia, já consagrado na Declaração Universal dos Direitos Humanos de $1948^{1}$, encontra igual proteção em diversos diplomasinternacionais e tais textos são estudados,pela literatura especializada sobre o direito à moradia ${ }^{2}$, de forma mais ou menos aprofundada, dependendo do enfoque trabalhado ${ }^{3}$.

São alguns deles: o Pacto Internacional sobre Direitos Civis e Políticos (Nova York, 1966) ${ }^{4}$; o Pacto Internacional sobre Direitos Econômicos, Sociais e Culturais (Nova York, 1966) ${ }^{5}$; a Convenção Internacional sobre a Eliminação de Todas as Formas de Discriminação Racial(Nova York, 1965) ${ }^{6}$; a Convenção sobre a Eliminação de Todas as Formas de Discriminação contra a Mulher(Nova York, 1979) ${ }^{7}$; a Convenção Internacional sobre os Direitos da Criança(Nova York, 1989) ${ }^{8}$; a Convenção Internacional sobre a Proteção dos Direitos de Todos os Trabalhadores Migrantes e dos Membros das suas Famílias (Nova York, 1990) ${ }^{9}$ e a Convenção Relativa ao Estatuto dos Refugiados (Genebra, 1951) ${ }^{10}$. Estes diplomas,preocupados em assegurar o direito à moradia adequada,estão temporalmente

\footnotetext{
1 Artigo XXV: "1. Toda pessoa tem direito a um padrão de vida capaz de assegurar a si e a sua família saúde e bem estar, inclusive alimentação, vestuário, habitação [...]” (ONU. Declaração Universal dos Direitos Humanos, 1948. Disponível em: <http://portal.mj.gov.br/sedh/ct/legis_intern/ddh_bib_inter_universal.htm> Acesso em: maio 2014.

${ }^{2}$ OSORIO, Letícia Marques. O direito à moradia como direito humano. In: FERNANDES, Edésio; ALFONSIN, Betânia (Coord.). Direito à moradia adequada: o que é, para quem serve, como defender e efetivar. Belo Horizonte: Fórum, 2014. p. 39-68.

${ }^{3}$ Cf. MILAGRES, Marcelo de Oliveira. Direito à moradia. São Paulo: Atlas, 2011.

${ }^{4}$ Ratificado pelo Decreto ${ }^{\circ}{ }^{\circ} 592$, de 6 de julho de 1992. (BRASIL. Decreto ${ }^{\circ}$ 592, de 6 de julho de 1992.Atos Internacionais. Pacto Internacional sobre Direitos Civis e Políticos. Promulgação.. Disponível em <http://www.planalto.gov.br/ccivil_03/decreto/1990-1994/D0592.htm> Acesso em: 04 de junho de 2014).

${ }^{5}$ Ratificado pelo Decreto $n^{\circ}$ 591, de 6 de julho de 1992.(BRASIL. Decreto ${ }^{\circ}$ 591, de 6 de julho de 1992. Atos Internacionais. Pacto Internacional sobre Direitos Econômicos, Sociais e Culturais. Promulgação. Disponível em <http://www.planalto.gov.br/ccivil_03/decreto/1990-1994/D0591.htm> Acesso em: 06 de maio de 2014).

${ }^{6}$ Ratificada pelo Decreto ${ }^{\circ}$ 65.810, de 8 de Dezembro de 1969. (BRASIL. Decreto $\mathrm{n}^{\circ}$ 65.810, de 8 de Dezembro de 1969. Promulga a Convenção Internacional sobre a Eliminação de todas as Formas de Discriminação Racial. Disponível em <http://www2.camara.leg.br/legin/fed/decret/1960-1969/decreto-65810-8-dezembro1969-407323-publicacaooriginal-1-pe.html> Acesso em: 06 de maio de 2014).

${ }^{7}$ Ratificado pelo Decreto $n^{\circ} 4.377$, de 13 de setembro de 2002. BRASIL. Decreto $n^{\circ} 4.377$, de 13 de setembro de 2002. Promulga a Convenção sobre a Eliminação de Todas as Formas de Discriminação contra a Mulher, de 1979, e revoga o Decreto no 89.460, de 20 de março de 1984. Disponível em < http://www.planalto.gov.br/ccivil_03/decreto/2002/D4377.htm> Acesso em: 06 de maio de 2014.

${ }^{8}$ Ratificado pelo Decreto $n^{\circ}$ 99.710, de 21 de novembro de 1990. (BRASIL. Decreto no 99.710, de 21 de novembro de 1990.Promulga a Convenção sobre os Direitos da Criança. Disponível em <http://www.planalto.gov.br/ccivil_03/decreto/1990-1994/D99710.htm> Acesso em: 06 de maio de 2014)

${ }^{9}$ Não ratificado pelo Brasil.

${ }^{10}$ Promulgada peloDecreto ${ }^{\mathrm{o}} 50.215$, de 28 de Janeiro de 1961. (BRASIL. Decreto $\mathrm{n}^{\mathrm{o}} 50.215$, de 28 de Janeiro de 196. .Promulga a Convenção relativa ao Estatuto dos Refugiados, concluída em Genebra, em 28 de julho de 1951.. Disponível em <http://www2.camara.leg.br/legin/fed/decret/1960-1969/decreto-50215-28-janeiro-1961389887-publicacaooriginal-1-pe.html> Acesso em: 04 de junho de 2014)
} 
distribuídos pelo intercurso temporal que vai da Declaração Universal dos Direitos Humanos (1948) até os dias atuais.

A proteção do direito à moradia no contexto dos pactos citados se dá no sentido de que para a garantida da dignidade do grupo protegido (a mulher, a criança, o refugiado, o trabalhador migrante) o direito à moradia é fator essencial. Mesmo que seja uma habitação temporária, preceitos mínimos de segurança e adequabilidade devem ser respeitados.

Pensando no contexto da América Latina nota-se que a questão do direito à moradia ainda é grave problema social. O relatório da ONU-Habitat de 2012, analisado adiante, demonstra que os problemas fundamentais acerca da moradia adequada ainda precisam de muitos avanços, pois é expressivo o número de pessoas que não tem acesso a nenhum tipo de moradia e que vivem em assentamentos precários.

No Brasil, em que pese ter sido positivado constitucionalmente apenas em 2010 (art. $6^{\circ}$, caput, EC n $\mathrm{n}^{\mathrm{0}}$ 64/2010), a interpretação do ordenamento jurídico brasileiro a partir das bases normativas precedentes da ordem jurídica internacional já lhe conferiam - ou ao menos deveriam conferir-lhe - eficácia plena. Assim, a inclusão do direito à moradia no rol dos direitos sociais não foi o marco inicial da sua proteção no ordenamento jurídico brasileiro.

A proteção do direito à moradia adequada nos textos internacionais não deve ser entendida como mera indicação ou recomendação de parâmetros a serem seguidos. Conforme previsto no Pacto Internacional de Direitos Econômicos, Sociais e Culturais - uma das fontes mais importantes do direito internacional na proteção da moradia adequada - em seu art. 11 ficou consignado que:

Os Estados Partes do presente Pacto reconhecem o direito de toda pessoa a um nível de vida adequado para si próprio e sua família, inclusive à alimentação, vestimenta e moradia adequadas, assim como a uma melhoria continua de suas condições de vida. Os Estados Partes tomarão medidas apropriadas para assegurar a consecução desse direito, reconhecendo, nesse sentido, a importância essencial da cooperação internacional fundada no livre consentimento ${ }^{11}$. (Grifos acrescidos)

O Pacto citado, como ratificado em 1992, já faz parte do ordenamento jurídico brasileiro há mais de duas décadas, assim como diversos outros que lhe antecederam, conforme enumeração apresentada anteriormente.

As Conferências Internacionais e as definições do Comitê dos Direitos Econômicos, Sociais e Culturais das Nações Unidas possuem importância fundamental na questão do

\footnotetext{
${ }^{11}$ BRASIL. Decreto $\mathrm{n}^{\mathrm{o}}$ 591, de 6 de julho de 1992. Atos Internacionais. Pacto Internacional sobre Direitos Econômicos, Sociais $\quad$ e $\quad$ Culturais. $\quad$ Promulgação. Disponível $\quad \mathrm{em}$ <http://www.planalto.gov.br/ccivil_03/decreto/1990-1994/D0591.htm> Acesso em: 06 de maio de 2014.
} 
Direito à Moradia. O Comentário Geral n. 4 do Comitê sobre os Direitos Econômicos, Sociais e Culturais, de 1991, por exemplo, deu novos contornos ao conceito de moradia adequada demonstrando se tratar de questão complexa e interligadaa outros direitos humanos fundamentais. Neste sentido,

\begin{abstract}
Segundo o ponto de vista do Comitê, o direito à habitação não deveria ser interpretado em um sentido estreito ou restrito que o equipara com, por exemplo, o abrigo provido meramente de um teto sobre a cabeça dos indivíduos ou julga o abrigo exclusivamente como uma mercadoria. Diferentemente, isso deveria ser visto mais propriamente como um direito a viver, onde quer que seja, com segurança, paz e dignidade. Isto é apropriado por, pelo menos, duas razões. Em primeiro lugar, o direito à habitação é integralmente vinculado a outros direitos humanos e a princípios fundamentais sobre os quais a Convenção é baseada. Esta "inerente dignidade da pessoa humana", de que os direitos na Convenção são ditos derivar, exige que o termo "habitação" seja interpretado de forma que leve em conta uma variedade de outras considerações, fundamentalmente que o direito à habitação deveria ser assegurado a todas as pessoas independentemente da renda ou acesso a recursos econômicos ${ }^{12}$.
\end{abstract}

Quando se está diante de extenso rol de normas internacionais acerca do direito à moradia, tem-se a impressão preliminar de que tal instituto jurídico não só deveria estar consolidado, como assimilado pela ordem jurídica interna e internacional, como será discutido a seguir, no contexto da América Latina e brasileiro.

\title{
3 O DIREITO À MORADIA NO CONTEXTO DA AMÉRICA LATINA (ONU- HABITAT)
}

O Programa das Nações Unidas para os assentamentos humanos (ONU-Habitat) divulgou relatório ${ }^{13}$ abordando os rumos da transição urbana na América Latina e Caribe. Para tratar desta transição foram destacados temas como o desenvolvimento econômico e justiça social, serviços públicos básicos, meio ambiente e governabilidade urbana, entre outros. O relatório destinou todo o Capítulo 3 para a questão da "Moradia, espaços públicos e convivência".

O citado Relatório aponta que nos últimos vinte anos houve avanço em termos qualitativos e quantitativos na questão habitacional da região analisada. No entanto, aponta

\footnotetext{
${ }^{12}$ Comentário Geral n. 4 do Comitê dos Direitos Econômicos Sociais e Culturais, 1991. Disponível em: <http://www2.ohchr.org/english/issues/housing/docs/CG4_sp.doc>. Acessoem: 4 de junho de 2014. .

${ }^{13}$ ONU-HABITAT. Programa de las Naciones Unidas para los Asentamientos Humanos. Estado de las ciudades de América Latina y el Caribe 2012: Rumbo a una nueva transición urbana, 2012. Disponívelem< http://www.onuhabitat.org/index.php?option=com_ docman\&task=cat_view\&gid=362\&Itemid=18 >. Acesso em: 23 de maio de 2014
} 
que ainda persistem várias deficiências que impedem a existência de moradia adequada para $\operatorname{todos}^{14}$.

Importante destacar que ao abordar do direito à moradia há grande preocupação emdesenvolver a noção de moradia adequada. Ou seja, não bastam "quatro paredes e um teto" para que se configure uma moradia. Existemoutros fatores que determinam se esta é adequada para atender à dignidade do cidadão ou não. E, além de fatores materiais como localização, acesso a serviços públicos básicos, condições de salubridade entre outros, existem fatores simbólicos ou afetivos ligados à noção de moradia. Tratam-se de fatores que podem ser mais difíceis de serem objetivados, mas que devem ser levados em consideração, por exemplo, o vínculo existente entre as pessoas e o lugar em que a moradia está localizada (caso das comunidades quilombolas, indígenas, povos tradicionais da América Latina, entre outros), ou as relações de vizinhança estabelecidas, ou mesmo a existência de laços consanguineos com determinadas famílias que ocupam o mesmo território. Este último caso pode ser exemplificado no processo de formação das favelas brasileiras. Ou ainda, a relação do morador que construiu a casa em que vive e possui uma série de relações afetivas com o lugar em que presenciou fatos importantes de sua vida. Assim, no Relatório da ONU-Habitat concluiu-se que:

A moradia não é apenas um teto para se abrigar, também é um lugar para viver e reunir a família. Para muitos, é o patrimônio mais importante em termos monetários e, por vezes, afetivo; o maior investimento de uma vida e, frequentemente, o lugar em que são gerados os recursos que suportam o lar. A moradia é, além disso, a unidade básica do crescimento urbano ${ }^{15}$.

O relatório se baseia em três aspectos para tratar da questão da moradia: o primeiro, a quantidade de moradias existentes (ou estoque habitacional); o segundo, a quantidade de moradias que faltam em função das existentes (déficit habitacional) e o terceiro, a quantidade de moradias que não cumprem os requisitos mínimos que permitam uma vida digna (déficit qualitativo).

O Relatório assinala que os próprios dados existentes e analisados apontam limitações e deficiências, pois estão concentrados apenas nos aspectos mais fáceis de quantificar. Ou seja, ainda existe um campo de pesquisa aberto no que tange a questão da

\footnotetext{
${ }^{14}$ Idem p. 62.

${ }^{15}$ ONU-HABITAT, 2012, p. 62, tradução livre do espanhol. "La vivienda no es solo un techo para abrigarse, tambien es un lugar para vivir y reunir a la familia. Para muchos, es el patrimonio mas importante en terminosmonetarios y, a veces, afectivo; la mayor inversion de una vida y, frecuentemente, el lugar donde se generan los recursos que sustentan el hogar. La vivienda es, ademas, la unidad basica del crecimiento urbano".
} 
moradia em seu aspecto qualitativo. Em que pese a dificuldade de análise de critérios subjetivos para se conceituar a adequabilidade da moradia, não é possível (ou mesmo desejável) fugir da relação subjetiva presente na questão da moradia adequada.

\subsection{O déficit habitacional quantitativo}

Conforme consta do relatório, quantificar o déficit habitacional não étarefa fácil. Notase que o número de moradias por mil habitantes nos países da região estudada oscila entre 200 e 300 (Fig. 1).

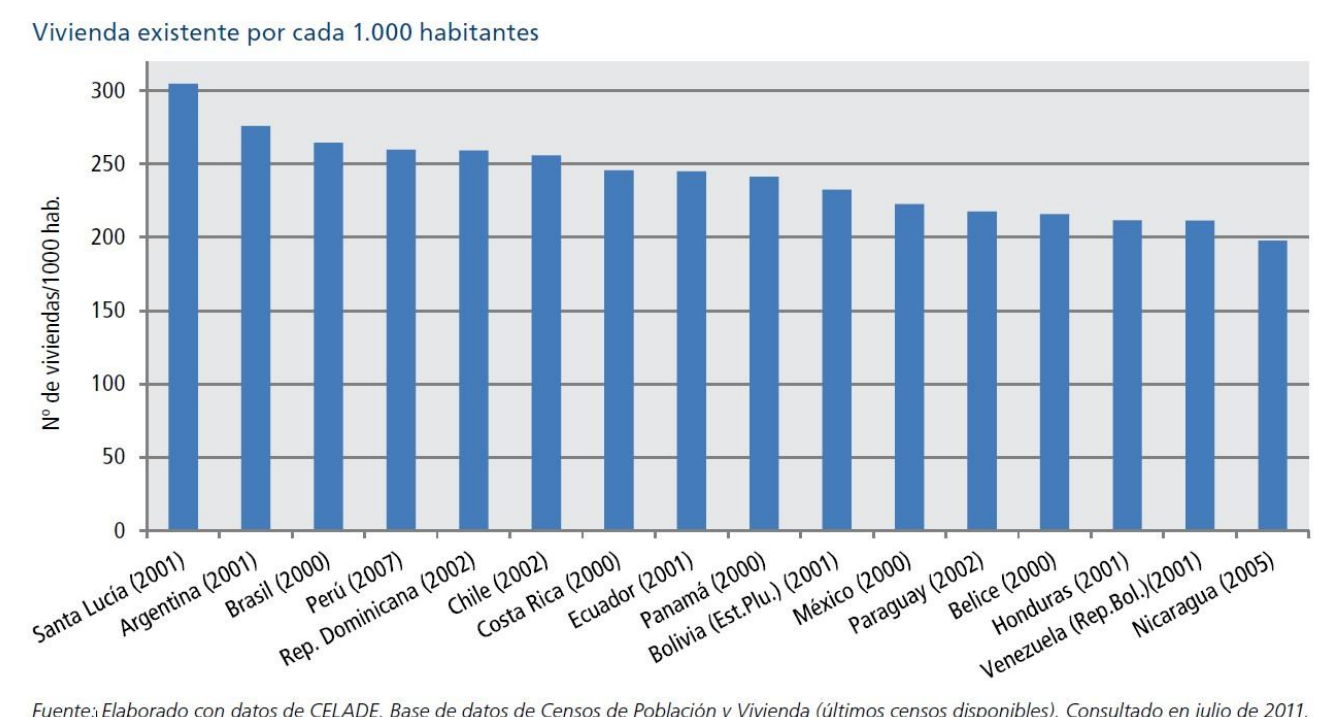

Fig. 1: Moradias existentes por 1.000 habitantes

No entanto, não há estudos que delimitem qual seria o número ideal. A existência de moradias por si só não é capaz de trazer maiores informações de como questões referentes a número de habitantes médios por moradia, ou moradias vazias etc.

Segundo consta do Relatório estudado, apesar do estoque habitacional existente, o déficit habitacional, entre 1990 e 2011, aumentou de 38 milhões de moradias para um valor entre 42 e 51 milhões de moradias na região ${ }^{16}$.

\subsection{O déficit habitacional qualitativo}

${ }^{16}$ ONU-HABITAT, 2012, p. 63. 
Como discutido anteriormente, analisar o déficit habitacional ultrapassa a questão quantitativa. Assim, segundo o Programa das Nações Unidas para os assentamentos humanos

Calcular as carências habitacionais é mais difícil do que estimar o déficit quantitativo, haja vista que se trata de um fenômeno amplo, com múltiplas causas e manifestações. Mesmo que em muitos países se note uma melhora no sistema de compilação de dados e unificação de critérios, o tipo de informação recebida ainda está longe depermitir um tipo de análise comparada e aceito do fenômeno ${ }^{17}$.

Visando orientar conclusões consistentes sobre a questão, foram definidos alguns critérios e parâmetros de análise para incluir no déficit habitacional qualitativo as inúmeras moradias queestão localizadas em ambientes que não cumprem requisitos mínimos para a ocupação humana. Devido à dificuldade de encontrar termos precisos e às diferenças culturais, os organismos internacionais usam de forma indiscriminada os termos "assentamentos precários", "bairros marginais" e "tugurios"18.

A ONU-Habitat define "assentamentos precários" como grupo de pessoas que vivem sob o mesmo teto em zona urbana que carece de uma ou mais das seguintes condições ${ }^{19}$ :

1 - uma moradia durável de natureza permanente que proteja contra condições climáticas adversas;

2- um espaço vital suficiente, o que significa que não mais de três pessoas compartilhem o mesmo quarto;

3 - acesso fácil a água potável em quantidade suficiente e a um preço razoável;

4 - acesso a saneamento adequado: latrina privada ou pública compartilhada por um número razoável de pessoas;

5 - posse segura para evitar despejos forçados.

A partir desta classificação, os dados levantados pela pesquisa demonstram que cerca de $25 \%$ da população da América Latina e Caribe, em média, vive em assentamentos precários e, em alguns países, a maioria da população vive neste tipo de assentamento, como demonstrado a seguir (Fig. 2):

\footnotetext{
${ }^{17}$ ONU-HABITAT, 2012, p. 63. Traduçãolivre de: "Evaluar las carencias habitacionales resulta aunmas difícil que estimar el déficit cuantitativo puesto que se trata de um fenómeno amplio, con múltiples causas y manifestaciones. Si bien en muchos países se ha mejorado el sistema de recopilación de datos y unificado algunos criterios, el tipo de información recabada todavía está lejos de permitir un análisis comparado y aceptado del fenómeno".

${ }^{18}$ Traduzido como habitação pequena e pobre, refúgio, abrigo. (Cf. MARTINEZ ALMOYNA, Julio. Dicionário de português-espanhol. Porto: Porto Editora, [19-], p. 1263).

19 ONU-HABITAT, 2012, p. 64.
} 
América Latina y el Caribe. Población urbana viviendo en tugurios, circa $2005^{\text {a }}$



a El promedio para América Latina y el Caribe incluye 27 países y territorios. Datos de 2005, con excepción de Argentina, Bolivia, Brasil, Colombia y Guatemala, que corresponden a 2007.

Fuente: ONU-Hábitat. Global indicators database. Procesamientos especiales de encuestas de hogares utilizando los 4 componentes de tugurio (agua mejorada, saneamiento mejorado, vivienda durable y área habitable suficiente).

Fig.2: População urbana vivendo em assentamentos precários (2005)

O Brasil está localizado próximo da média dos países pesquisados, ou seja, 25\% da sua população vive nestes tipos de assentamentos. No entanto, por ser o país mais populoso em números absolutos, provavelmente é o que possui também o maior número de pessoas vivendo em condições precárias no que tange à situação de moradia.

O Relatório estudado aponta para a melhoria de condições nos assentamentos precários existentes sendo que na América Latina e Caribe o número absoluto de pessoas vivendo em assentamentos precários tem diminuído. No entanto, algumas exceções são o caso do Haiti e do Brasil. O primeiro País devido aos efeitos do terremoto de 2010 e o Brasil, pelo crescimento, nos últimos 20 anos, de 5 milhões de pessoas vivendo em assentamento precários. $^{20}$

\section{MORADIA, POSSE E PROPRIEDADE}

Um ponto importante destacado no citado Relatório é a relação entre o direito de moradia e os direitos de posse e propriedade. Na região pesquisada a forma predominante para a efetivação do direito à moradia é a propriedade da moradia por quem nela vive. $\mathrm{O}$ Relatório, no entanto, faz importante ressalva, ao concluir que a afirmação de que se é proprietário de determinado terreno ou moradia não significa necessariamente que exista um

${ }^{20}$ ONU-HABITAT, 2012, p. 65. 
título legalmente reconhecido que garanta a propriedade de determinado bem, havendo, em muitos casos, notadamente em assentamentos informais, apenas a situação de posse. Segundo os dados levantados tem-se que:

\begin{abstract}
Em todos os países com disponibilidade de dados, mais da metade dos moradores urbanos se declara proprietário do lugar em que vive. No entanto, isto não significa que possuam um título de propriedade conforme a legislação vigente. Em muitos países, entre eles Argentina e Brasil, o termo é identificado com a propriedade da estrutura física, ou seja, a própria moradia, não com a propriedade do solo, nem com a existência ou não de um título de propriedade. Tão pouco faz referência se a moradia ou o bairro possui reconhecimento urbanístico ou cumpre com os requisitos jurídicos exigidos para ter condição urbana segundo as normas de planejamento da cidade ${ }^{21}$.
\end{abstract}

O conjunto de informaçõespresentes no Relatório da ONU-Habitatde 2012 dão conta do complexo cenário em que o direito à moradia, e os direitos de posse e propriedade estão envolvidos, considerando o contex to em que a maior parte das pessoas se considera proprietária da sua moradia em que pese, se analisadas sob a ótica direito nacional, deterem apenas a posse.

$\mathrm{O}$ ordenamento jurídico brasileiro não define o direito de propriedade. O Código Civil de $2002 \mathrm{em}$ seu art. $1.228^{22}$ define apenas as faculdades do proprietário. Com base nestas faculdades do domínio, aliteratura acerca dos direitos reais debate se a posse deve ser considerada como direito autônomo ou se seria apenas a exteriorização do direito de propriedade permanecendo vinculada a este ${ }^{23}$. Tal debate é importante para a proteção do direito à moradia, haja vista que em muitos casos a posse do morador não coincide com a propriedade (formal/legal) da moradia.

Para Edésio Fernandes,

Nunca houve reforma do paradigma liberal clássico, ou seja, ainda se aplica de maneira dominante o paradigma tradicional dos direitos individuais da propriedade vista quase tão-somente como uma mercadoria, uma propriedade cujo conteúdo econômico é predeterminado pelo interesse individual do proprietário, sendo o

\footnotetext{
${ }^{21}$ ONU-HABITAT, 2012, p. 66. Traduçãolivre do espanhol: "En todos los países con disponibilidad de datos, más de la mitad de los hogares urbanos se declara propietario del lugar donde vive. Sin embargo, esto no significa que posean un título de propiedad conforme a la legislación vigente. En muchos países, entre ellos Argentina y Brasil, el termino se identifica con la propiedad de la estructura física, es decir, la propia vivienda, no con la propiedad del suelo, ni con la existencia o no de un título de propiedad. Tampoco hace referencia a si la vivienda o el barrio tiene reconocimiento urbanístico o cumple con los requisitos jurídicos exigidos para tener condición urbana según las normas de planeación de la ciudad".
}

22، Art. 1.228. O proprietário tem a faculdade de usar, gozar e dispor da coisa, e o direito de reavê-la do poder de quem quer que injustamente a possua ou detenha. [...]" (BRASIL, Lein ${ }^{\circ}$ 10.406, DE 10 DE JANEIRO DE 2002.Institui o Código Civil. Disponível em: <http://www.planalto.gov.br/ccivil_03/leis/2002/110406.htm>. Acesso em 8 de junho de 2014).

${ }^{23}$ Cf. MILAGRES, Marcelo de Oliveira. Direito à moradia. São Paulo: Atlas, 2011. 
escopo de ação do poder público extremamente limitado e com pouquíssimas considerações de valores ambientais e sociais ${ }^{24}$.

Conforme dados coletados (Fig. 3), é bastante elevado na América Latina e Caribe o percentual de domicílios, cuja condição jurídica da moradia é tida como de proprietário:

Distribución de hogares urbanos por condición jurídica de la tenencia de la vivienda. Circa 2007
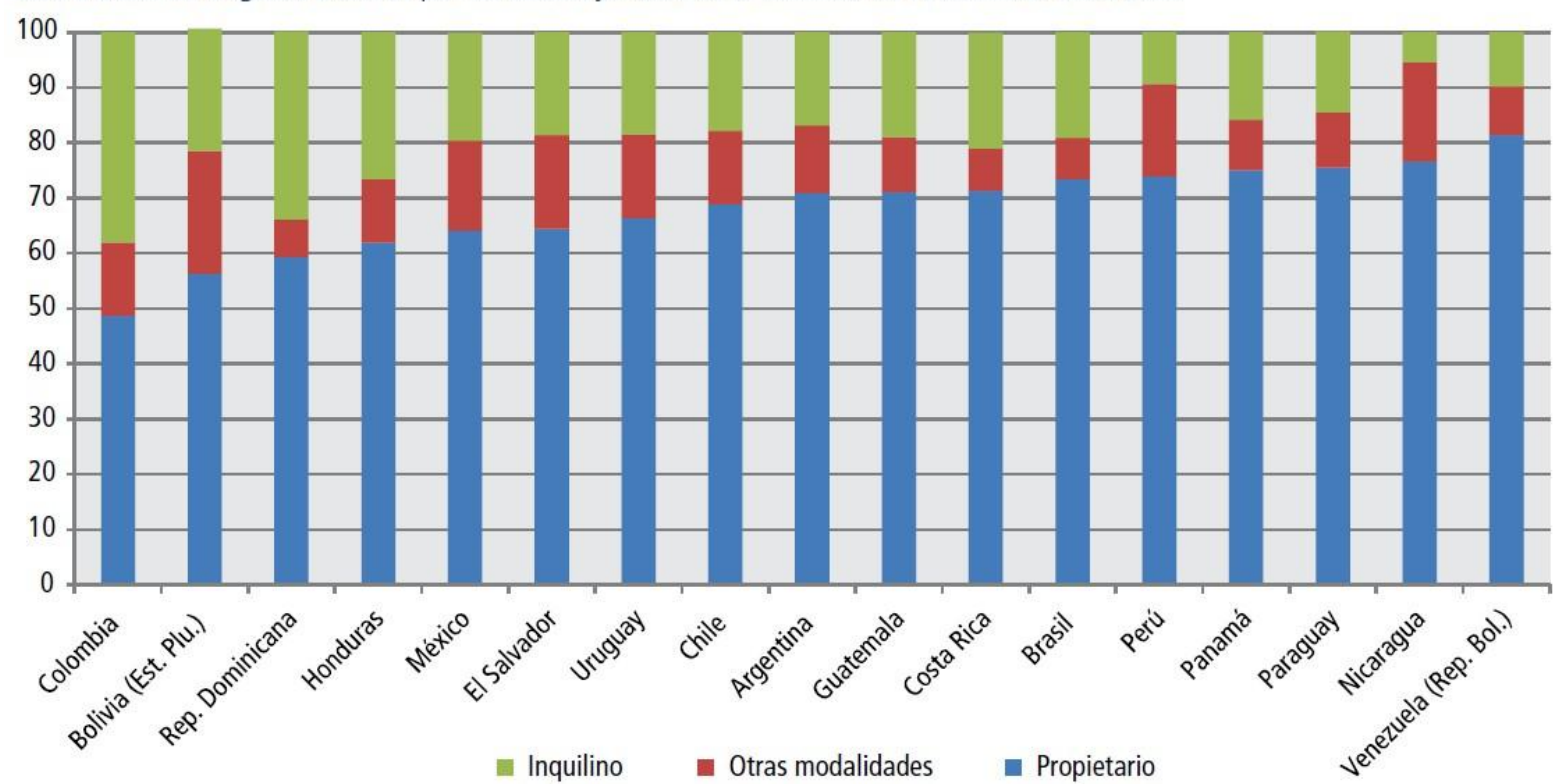

Fuente: Elaboración con datos de la CEPAL, División de Estadistica y Proyecciones Económicas, sobre la base de tabulaciones especiales de las encuestas de hogares de los respectivos paises. Paises seleccionados para esta ilustración gráfica.

Fig. 3: distribuição dos domicílios urbanos conforme a condição jurídica da posse da moradia

No entanto, se não existe título de propriedade ou mesmo se essa moradia não está situada em um lugar com os padrões urbanísticos mínimos descritos anteriormente, estas pessoas, conforme a classificação da ONU, vivem em assentamentos precários.

É importante ressaltar que ao se afirmar proprietário de uma moradia sem que esta esteja amparada pela propriedade legalmente constituída do solo em que a construção foi realizada, torna-se frágil o exercício do direito à moradia adequada.

Cabe ressaltar que o Relatório aborda o Programa "Minha Casa, Minha Vida" 25 como uma das medidas que os governos dos países da América Latina e Caribe vem tomando

\footnotetext{
${ }^{24}$ FERNANDES, Edésio. A nova ordem jurídico-urbanística no Brasil. In: FERNANDES, Edésio; ALFONSIN, Betânia (org.) Direito urbanístico: estudos brasileiros e internacionais. Belo Horizonte: Del Rey, 2006, p. 14.

${ }^{25}$ O Programa Minha Casa, Minha Vida - PMCMV tem por finalidade criar mecanismos de incentivo à produção e aquisição de novas unidades habitacionais ou requalificação de imóveis urbanos e produção ou reforma de habitações rurais, para famílias com renda mensal de até $\mathrm{R} \$ 4.650,00$. O PMCMV compreende ainda os subprogramas: o Programa Nacional de Habitação Urbana - PNHU e o Programa Nacional de Habitação Rural PNHR. (Cf. BRASIL. LEI No 11.977, DE 7 DE JULHO DE 2009. Dispõe sobre o Programa Minha Casa, Minha Vida - PMCMV e a regularização fundiária de assentamentos localizados em áreas urbanas; altera o Decreto-Lei no 3.365, de 21 de junho de 1941, as Leis nos 4.380, de 21 de agosto de 1964, 6.015, de 31 de dezembro de 1973, 8.036, de 11 de maio de 1990, e 10.257, de 10 de julho de 2001, e a Medida Provisória no 2.197-43, de 24
} 
para incentivar a construção de moradias, principalmente para as pessoas de mais baixa renda $^{26}$.

\subsection{Direito à moradia e segurança da posse}

O direito à moradia ultrapassa a relação direta com o direito à propriedade. O Relatório aborda o subsídio de aluguéis, por exemplo, como forma de redução do déficit habitacional e garantia de moradia adequada. Além disso, os procedimentos de titulação de moradias não precisam resultar necessariamente na concessão do título individual de propriedade. Outra possibilidade é o título coletivo, ou ainda, a garantia da posse por períodos determinados.

O Relatório destaca ainda que a segurança jurídica da posse pode se alcançar em outras situações como a segurança para inquilinos ou com a chamada "legalização" de assentamentos irregulares. Assim,

\footnotetext{
Uma tarefa pendente na América Latina é a proteção da segurança jurídica da posse de inquilinos. Boa parte das residências não dispõe de contrato escrito, ou mesmo quando tem, desconhece a legislação; também há casos em que, mesmo sendo conhecida, esta não se aplica.
}

No que diz respeito a posse dos assentamentos de origem irregular, cabe destacar que a região tem mais de quarenta anos de experiência na redefinição dos direitos de propriedade nestes contextos. Muitas cidades têm realizado o que é conhecido genericamente como titulação, ou seja, legalizar a posse de lotes individuais para as famílias que os ocupam. Com foco e escopo diferente, foram identificadas tais políticas em pelo menos 17 países da América Latina e do Caribe ${ }^{27}$.

Os grupos de pessoas vulneráveis que ocuparam áreas de risco ou mesmo áreas em que não há a proteção legal enfrentam a insegurança da posse com relação à moradia em que vivem.

de agosto de 2001; e dá outras providências. Disponível em: < http://www.planalto.gov.br/ccivil_03/_ato20072010/2009/lei/111977.htm>. Acesso em: 04 de junho de 2014).

${ }^{26}$ Para uma abordagem crítica da questão da habitação no Brasil e do Programa Minha Casa Minha Vida Cf. MARICATO, Ermínia. O impasse da política urbana no Brasil. Petrópolis, RJ: Vozes, 2011.

27 ONU-HABITAT, 2012, p. 67. Tradução do espanhol de: “Una tarea pendiente en America Latina es la protección de la seguridad juridica de la tenencia de los arrendatarios. Buena parte de los hogares no dispone de un contrato escrito o, incluso cuando lo tiene, desconoce la legislacion; tambien se dan casos en que, aun conociendola, no se aplica. Respecto a la tenencia de los asentamientos de origen irregular, cabe destacar que la region cuenta con mas de cuarenta anos de experiencias de redefinicion de los derechos de propiedad en estos contextos. Numerosas ciudades han procedido a lo que genericamente se conoce como titulacion, es decir legalizar la tenencia de lotes individuales a favor de las familias que los ocupan. Con diferentes focos y alcances, se han identificado este tipo de politicas en al menos 17 paises de America Latina y el Caribe”. 
A relatora especial da $\mathrm{ONU}^{28}$, Raquel Ronilk, em informe sobre moradia adequada, demonstra que há uma crise mundial de insegurança da posse que afeta os domicílios de milhares de pessoas que residem em áreas urbanas com posse insegura. Esta insegurança manifesta-se de várias formas em contextos distintos, tais como remoções e despejos forçados, deslocamentos causados pelo desenvolvimento, catástrofes naturais, além dos conflitos de grilagem ${ }^{29}$.

A segurança na posse é elemento fundamental ao direito à moradia adequada, conforme demonstrado pela ONU-Habitat ${ }^{30}$ e pela Assembleia das Nações Unidas, sobretudo em seus relatórios especiais ${ }^{31}$. A segurança na posse foi reconhecida juridicamente em virtude do direito internacional dos direitos humanos ${ }^{32}$.

\title{
O Comentário Geral no 4 (1991) do Comitê de Direitos Econômicos, Sociais e
}

Culturais da ONU, ao tratar da segurança jurídica da posse como um dos requisitos para a moradia adequada conclui que:

\begin{abstract}
A posse toma uma variedade de formas, incluindo locação (pública e privada) acomodação, habitação cooperativa, arrendamento, uso pelo próprio proprietário, habitação de emergência e assentamentos informais, incluindo ocupação de terreno ou propriedade. Independentemente do tipo de posse, todas as pessoas deveriam possuir um grau de sua segurança, o qual garanta proteção legal contra despejos forçados, pressões incômodas e outras ameaças. Estados-partes deveriam, consequientemente, tomar medidas imediatas com o objetivo de conferir segurança jurídica de posse sobre pessoas e domicílios em que falta proteção, em consulta real com pessoas e grupos afetados ${ }^{33}$.
\end{abstract}

A importância da segurança da posse é evidente para que a moradia adequada se efetive. A concepção clássica de propriedade, formulada pelo Direito Civil no Séc. XIX, é uma forma de se garantir esta segurança: trata-se da propriedade formal, protegida por um título de propriedade, que assegura segurança e tranquilidade para o proprietário. No entanto, esta não é a única forma de se garantir a segurança da posse.

Em informativo mais recente sobre a moradia adequada, problematizando a necessária relação entre moradia e direito de propriedade, a relatora especial da ONU sugere

\footnotetext{
${ }^{28}$ Informe de la Relatora Especial sobre una vivienda adecuada como elemento integrante del derecho a un nivel de vida adecuado y sobre el derecho de no discriminación a este respecto, Raquel Rolnik. Disponível em: <http://www.ohchr.org/EN/Issues/Housing/Pages/HousingIndex.aspx e em www.direitoamoradia.org>.

${ }^{29}$ Informe de la Relatora Especial sobre una vivienda adecuada como elemento integrante del derecho a un nivel de vida adecuado y sobre el derecho de no discriminación a este respecto, Raquel Rolnik, 2012, p. 1.

${ }^{30}$ ONU-HABITAT. El derecho a una vivienda adecuada. Folleto informativo No 21/Rev.1. Disponível em: <www. http://www.ohchr.org/Documents/Publications/FS21_rev_1_Housing_sp.pdf.>Acesso em: 04 de junho de 2014.

${ }^{31}$ ONU-HABITAT, 2012.

${ }^{32}$ Informe de la Relatora Especial sobre una vivienda adecuada como elemento integrante del derecho a un nivel de vida adecuado y sobre el derecho de no discriminación a este respecto, Raquel Rolnik, 2012, p. 12.

${ }^{33}$ Comentário Geral n. ${ }^{\circ} 4$ do Comitê dos Direitos Econômicos Sociais e Culturais, 1991. Disponível em: <http://www2.ohchr.org/english/issues/housing/docs/CG4_sp.doc>. Acessoem: 04 de junho de 2014.
} 
aos Estados que seja modificado, inclusive, o paradigma das políticas públicas de acesso à moradia, que devem passar de políticas baseadas no financiamento da moradia para a adoção de políticas centradas nos direitos humanos,incluindo alugueis públicos e privados e posse coletiva. 34

Ademais, como já citado, a moradia não deve ser compreendida apenas como um "teto e quatro paredes" ou como mercadoria. Desse modo, a aquisição no mercado de uma habitação e a segurança dos títulos de compra e venda e de propriedade não podem ser as únicas formas de se garantir o direito fundamental à moradia adequada.

No contexto dos países da América Latina fica claro que as desigualdades sociais e econômicas não permitem que a noção da moradia como mercadoria possa prevalecer. Formas coletivas de habitação e a segurança da posse independente do vínculo de propriedade são algumas formas que precisam ser consideradas na busca da efetivação deste direito, o que leva à discussão da questão jurídica da função social da propriedade. Os debates acerca deste assunto alcançam uma gama de temas, entre os quais se destaca o acesso à moradia nos imóveis urbanos vazios (edificados ou não).

Autores, como Marcelo Milagres ${ }^{35}$, vão citar que o direito à moradia deve prevalecer em relação ao direito de propriedade, pois este seria um direito dispensável enquanto aquele não. Para outros, como Letícia Osório, o direito à moradia possui vínculo direto com o direito fundamental à propriedade formando seu "conteúdo existencial". Para a autora,

\begin{abstract}
Morar constitui um existencial humano [...] porque engloba o direito de ocupar um lugar no espaço e as condições que tornam adequadas tal lugar para moradia. É neste contexto que o vínculo direto entre direito à moradia e garantia de um mínimo existencial materializam-se, constituindo-se, para tanto, como conteúdo existencial de outros direitos fundamentais, tais como o direito de propriedade ${ }^{36}$.
\end{abstract}

De maneira contrária, Copello, ao descrever a questão urbana na Colômbia, afirma que o direito à propriedade sequer constitui direito fundamental. Segundo a autorao que o direito garante é a função social da propriedade, de forma que se não há função (dever) não há propriedade. E explica:

De maneira esquemática os avanços do regime constitucional da propriedade (disposições e jurisprudência constitucional) podem ser resumidos assim:

\footnotetext{
${ }^{34}$ La Relatora pide que se modifique el paradigma, pasando de las políticas basadas en la financialización de la vivienda a la adopción de un enfoque de estas políticas centrado en los derechos humanos y recomienda que los Estados promuevan distintas formas de tenencia, incluidos los alquileres privados y públicos y la tenencia colectiva. (p. 2, resumen)

${ }^{35}$ MILAGRES, 2011. Tal defesa é realizada no decorrer da obra citada.

${ }^{36}$ OSORIO, 2014, p.44.
} 


\begin{abstract}
A propriedade não é um direito fundamental, o que se expressou pela sistemática negativa da Corte Constitucional a receber demandas de tutela do direito de propriedade, porque este mecanismo se dirige exclusivamente a proteger direitos fundamentais. Apenas se aceita o trâmite deste tipo de ação, de maneira excepcional, quando o exercício da propriedade está em direta e clara conexão com outros direitos fundamentais [...].

Neste contexto é possível ir mais além ao ponto de afirmar que a propriedade nem sequer seria um direito, já que constitucionalmente está definida como uma função social e ecológica. Numerosos juristas colombianos e a Corte Constitucional tem reafirmado claramente este princípio. O que a Constituição garante é a função social da propriedade, que se traduz no nível mínimo de desfrute que outorgue um interesse para o proprietário de possuir um determinado bem ${ }^{37}$..
\end{abstract}

No Brasil o fenômeno das ocupações urbanas congrega uma série de fatores aqui trabalhados. O déficit habitacional e o elevado preço das moradias (tanto para compra quanto para o aluguel) resultam em elevado número de pessoas que vivem nessas ocupações ${ }^{38}$.Os ocupantes convivem com a precarização das moradias e com a incerteza quanto a posse do lugar em que vivem. O Estado - notadamente no contexto brasileiro - ao invés de buscar formas de efetivar a segurança da posse, é responsável pela expulsão dos moradores da ocupação, disponibilizando o aparato policial necessário para o cumprimento de decisões judiciais de despejo. A forma de regulação da propriedade privada urbana e a ação limitada do poder público para tornar efetivo novo paradigma jurídico revelam que a função social da propriedade ainda não é considerada fonte de mudança e de justiça social, a partir da ordem jurídica.

O Comitê para os Direitos Humanos e Sociais citado no Relatório sobre a segurança na posse, de 2012, enfatizou que

[...] qualquer que seja o tipo de posse, todas as pessoas devem possuir um grau de segurança de posse que garanta a proteção legal contra o despejo forçado, assédio e outras ameaças. Nesse sentido, os Estados Partes devem tomar medidas imediatas

\footnotetext{
37 COPELLO, María Mercedes Maldonado. El proceso de construcción del sistema urbanístico colombiano: entre reforma urbana y ordenamiento territorial. IN: FERNANDES, Edesio; ALFONSIN, Betânia de Moraes. Direito urbanístico: estudos brasileiros e internacionais. Belo Horizonte: Del Rey, 2006. p. 34-35. Tradução do espanhol de: "De manera esquemática los avances del régimen constitucional de la propiedad (disposiciones y jurisprudencia constitucionales) se pueden resumir así:

La propiedad no es un derecho fundamental, lo que se ha expresado en la sistemática negativa de la Corte Constitucional a aceptar demandas de tutela del derecho de propiedad, porque este mecanismo se dirige exclusivamente a proteger derechos fundamentales. Sólo se acepta el trámite de este tipo de acciones, de manera muy excepcional, cuando el ejercicio de la propiedad está en directa y clara conexión con otros derechos fundamentales. [...] En este contexto es posible ir más allá, al punto de afirmar que la propiedad ni siquiera seria un derecho, ya que constitucionalmente está definida como una función social y ecológica. Numerosos juristas colombianos y la Corte Constitucional han reafirmado claramente este principio. Lo que la Constitución garantiza es la función social de la propiedad; que se traduce en el nivel mínimo de desfrute que otorgue un interés para el propietario de poseer un determinado bien".

${ }^{38} \mathrm{O}$ conceito de ocupação urbana e sua diferenciação de outras formas de assentamentos é discutida a partir de pesquisa empírica e análise do estudo da Ocupação Dandara, localizada em Belo Horizonte-MG, em DIAS et al. Ocupações urbanas e direito à cidade: excertos da cartografia sociojurídica da comunidade Dandara, em Belo Horizonte. In: DIAS, M. T. F; BARBOSA, M. E. B.; COSTA, M. B. C; CORDEIRO, C. Estado e propriedade: estudos em homenagem à Professora Maria Coeli Simões Pires. Belo Horizonte: Fórum, 2014 (no prelo)
} 
para conferir segurança jurídica da posse sobre as pessoas e as famílias, vez que atualmente não existe esta proteção, em consulta genuína com as pessoas e grupos $\operatorname{afetados}^{39}$

A questão talvez mais importante que precisa avançar, neste contexto, sobretudo no Brasil, são os processos de monitoramento da segurança na posse ${ }^{40}$ para o acesso à moradia adequada, vez que são as populações mais vulneráveis as que mais têm turbado o seu direito de moradia adequada.

\section{CONCLUSÃO}

O presente trabalho visa contribuir para o debate quanto à necessidade de se garantir moradia adequada para todos que ainda não tenham esse direito efetivado. Destacou-se o importante papel do direito internacional na proteção do instituto e no desenvolvimento do seu conceito de forma profunda. A noção de que o direito à moradia adequada vai além de "um teto e quatro paredes" é valiosa para que na promoção de políticas públicas habitacionais a relevância e complexidade deste direito esteja em pauta. Além disso, como direito fundamental e garantia de todo cidadão, o Estado deve se preocupar em garantir a moradia adequada, e não tratá-la apenas como mercadoria que pode ser adquirida pelos indivíduos.

O trabalho chama a atenção para a característica da segurança da posse, pois este requisito da adequabilidade da moradia é de extrema relevância para garantir o mínimo de tranquilidade para o morador. Para que se garanta a dignidade da pessoa ela deve possuir um abrigo pelo tempo que precise, sem temer despejos forçados ou a retirada compulsória (sem indenização prévia ou o devido processo) do lugar em que vive.

Com base no que foi discutido buscou-se responder parte das indagações levantadas no texto:

1. O direito à moradia internacionalmente protegido não deve estar vinculado ao direito de propriedade, pois outras possibilidadesassinaladas pelo Relatório da ONU (2012) apontamo subsídio de alugueis ou a titulação de áreas de ocupação irregularcomo outros instrumentos a serem utilizados nas políticas habitacionais. Além disso, ao traçar diretrizes

\footnotetext{
${ }^{39}$ Relatório temático sobre segurança da posse dos pobres urbanos apresentado pela Relatora Especial para o Direito à Moradia Adequada, Raquel Rolnik, na 25 Sessão do Conselho de Direitos Humanos da ONU, em Março de 2014. p. 12. O relatório (A/HRC/25/54) está disponível em: http://www.ohchr.org/EN/Issues/Housing/Pages/HousingIndex.aspx e em www.direitoamoradia.org. O Conselho de Direitos Humanos, ao final da sua $25^{\text {a }}$ Sessão, adotou uma resolução (A/HRC/25/L.18) que inclui referências à segurança da posse, a estas diretrizes e ao relatório apresentado pela Relatora.

${ }^{40}$ SAULE JÚNIOR, Nelson. Instrumentos de monitoramento do direito humano a moradia adequada. In: FERNANDES, Edésio; ALFONSIN, Betânia. Direito Urbanístico: estudos brasileiros e internacionais. Belo Horizonte: Del Rey, 2006. p. 215-250.
} 
para a segurança da posse dos pobres urbanos, o Relatório afirma que devem ser fortalecidas diversas formas de posse: direitos de posse, direitos de uso, aluguel, propriedade privada e arranjos coletivos.

2. A solução para a questão do exercício ao direito à moradia adequada não está relacionada apenas à regularização fundiária dos assentamentos informais com a distribuição de títulos individuais de propriedade. O título individual de propriedade é uma forma de efetivação do direito à moradia. E por ser a forma predominante no contexto da América Latina e Caribe não pode ser ignorada. No entanto, $25 \%$ da população não está contemplada por este instrumento. Além disso, não basta conceder o título de propriedade, pois a regularização fundiária também deve estar pautada pela criação de infra-estrutura urbana, pois via de regra, o fato de não existir título de propriedade coincide com condições precárias de habitação e acesso a outros serviços públicos básicos.

3. Outras formas de propriedade, como a propriedade coletiva ou condomínios deveriam ser estabelecidos. Se a efetivação do direito à moradia baseado na concepção vigente de propriedade privada não consegue alcançar a todos é preciso pensar em outras formas de realização deste direito subjetivo. Caso contrário isso significaria aceitar que parte da sociedade ficará impossibilitada de acessar o direito à moradia adequada.

4. A noção de função social da propriedade, também positivada no ordenamento jurídico pátrio (art. $5^{\circ}$, XXIII, da CR/1988)já deveria ser suficiente para reduzir as desigualdades sociais existentes nesse campo. A função social da propriedade está presente no ordenamento brasileiro desde a Constituição de 1934. No entanto, é a partir do texto constitucional de 1988 que tal noção ganha corpo no debate político, jurídico e social. Todavia, passados mais de 25 anos os avanços práticos quanto a aplicação da função social da propriedade se mostram insuficiente.O contexto da América Latina, ilustrado neste trabalho, demonstra que ainda é necessário avançar muito para que a moradia adequada seja efetiva e correspondaa determinada realidade que atenda ao que já está disciplinado no direito internacional e seja reconhecido pelo direito brasileiro.O papel do direito, neste momento, talvez seja contribuir com formas efetivas de se garantir segurança jurídica da posse para pessoas que ocupam assentamentos precários. Para tanto a aplicação do princípio da função social da propriedade como finalidade e condição de toda propriedade poderia contribuir para a redução de desigualdades e promoção do direito à moradia adequada. Esta não é uma questão simples, haja vista que o papel da propriedade privada no campo econômico e mesmo simbolicamente na sociedade capitalista é elemento de conflito social e instituto jurídico de tradição e conteúdo histórico de difícil alteração imediata. No entanto, dificuldades para 
pensar novas formas de reger a propriedade privada não podem inviabilizar que o direito à moradia adequada seja efetivado.

\section{REFERÊNCIAS}

BRASIL. Decreto $\mathrm{n}^{\circ}$ 50.215, de 28 de Janeiro de 1961. .Promulga a Convenção relativa ao Estatuto dos Refugiados, concluída em Genebra, em 28 de julho de 1951. Disponível em <http://www2.camara.leg.br/legin/fed/decret/1960-1969/decreto-50215-28-janeiro-1961389887-publicacaooriginal-1-pe.html> Acesso em: 04 de junho de 2014.

BRASIL.Decreto $n^{\circ}$ 65.810, de 8 de Dezembro de 1969. Promulga a Convenção Internacional sobre a Eliminação de todas as Formas de Discriminação Racial. Disponível em <http://www2.camara.leg.br/legin/fed/decret/1960-1969/decreto-65810-8-dezembro-1969407323-publicacaooriginal-1-pe.html> Acesso em: 06 de maio de 2014.

BRASIL. Decreto ${ }^{\circ}$ 99.710, de 21 de novembro de 1990.Promulga a Convenção sobre os Direitos da Criança. Disponível em <http://www.planalto.gov.br/ccivil_03/decreto/19901994/D99710.htm> Acesso em: 06 de maio de 2014.

BRASIL. Decreto $n^{\circ}$ 591, de 6 de julho de 1992. Atos Internacionais. Pacto Internacional sobre Direitos Econômicos, Sociais e Culturais. Promulgação. Disponível em <http://www.planalto.gov.br/ccivil_03/decreto/1990-1994/D0591.htm> Acesso em: 06 de maio de 2014.

BRASIL. Decreto $\mathrm{n}^{\circ}$ 592, de 6 de julho de 1992.Atos Internacionais. Pacto Internacional sobre Direitos Civis e Políticos. Promulgação. Disponível em <http://www.planalto.gov.br/ccivil_03/decreto/1990-1994/D0592.htm> Acesso em: 04 de junho de 2014.

BRASIL, Lei $\mathrm{n}^{\circ}$ 10.406, de 10 dejaneirode 2002.Institui o Código Civil. Disponível em: <http://www.planalto.gov.br/ccivil_03/leis/2002/110406.htm>. Acesso em 08 de junho de 2014.

BRASIL. Decreto $\mathrm{n}^{\circ}$ 4.377, de 13 de setembro de 2002. Promulga a Convenção sobre a Eliminação de Todas as Formas de Discriminação contra a Mulher, de 1979, e revoga o Decreto no 89.460, de 20 de março de 1984. Disponível em <http://www.planalto.gov.br/ccivil_03/decreto/2002/D4377.htm> Acesso em: 06 de maio de 2014.

BRASIL. Lei ${ }^{\circ}$ 11.977, de 7 de julho de 2009. Dispõe sobre o Programa Minha Casa, Minha Vida - PMCMV e a regularização fundiária de assentamentos localizados em áreas urbanas; altera o Decreto-Lei no 3.365, de 21 de junho de 1941, as Leis nos 4.380, de 21 de agosto de 1964, 6.015, de 31 de dezembro de 1973, 8.036, de 11 de maio de 1990, e 10.257, de 10 de julho de 2001, e a Medida Provisória no2.197-43, de 24 de agosto de 2001; e dá outras providências. Disponível em: <http://www.planalto.gov.br/ccivil_03/_ato20072010/2009/lei/111977.htm>. Acesso em: 04 de junho de 2014. 
Comentário Geral n. ${ }^{\circ} 4$ do Comitê dos Direitos Econômicos Sociais e Culturais, 1991. Disponível em: <http://www2.ohchr.org/english/issues/housing/docs/CG4_sp.doc>. Acesso em: 04 de junho de 2014.

COPELLO, María Mercedes Maldonado. El proceso de construcción del sistema urbanístico colombiano: entre reforma urbana y ordenamiento territorial. In:FERNANDES, Edesio; ALFONSIN, Betânia de Moraes. Direito urbanístico: estudos brasileiros e internacionais. Belo Horizonte: Del Rey, 2006. P. 25-58.

DIAS et al. Ocupações urbanas e direito à cidade: Excertos da cartografia sociojurídica da comunidade Dandara, em Belo Horizonte. In: DIAS, M. T. F; BARBOSA, M. E. B.; COSTA, M. B. C; CORDEIRO, C. Estado e propriedade: estudos em homenagem à Professora Maria Coeli Simões Pires. Belo Horizonte: Fórum, 2014 (no prelo)

FERNANDES, Edésio. A nova ordem jurídico-urbanística no Brasil. In: FERNANDES, Edésio; ALFONSIN, Betânia (org.) Direito urbanístico: estudos brasileiros e internacionais. Belo Horizonte: Del Rey, 2006. p. 3 - 23.

MARICATO, Ermínia. O impasse da política urbana no Brasil. Petrópolis, RJ: Vozes, 2011. $219 \mathrm{p}$.

MARTINEZ ALMOYNA, Julio. Dicionario de português-espanhol. Porto: Porto Editora, [19]. 1332p.

MILAGRES, Marcelo de Oliveira. Direito à moradia. São Paulo: Atlas, 2011.

ONU. Declaração Universal dos Direitos Humanos, 1948. Disponível em: «http://portal.mj.gov.br/sedh/ct/legis_intern/ddh_bib_inter_universal.htm» Acesso em: maio 2014

ONU-HABITAT. Programa de las Naciones Unidas para los Asentamientos Humanos. Estado de las ciudades de América Latina y el Caribe 2012: Rumbo a una nueva transición urbana, 2012. Disponívelem< http://www.onuhabitat.org/index.php?option=com_ docman\&task=cat_view\&gid=362\&Itemid=18 >. Acesso em: 23 de maio de 2014 .

ONU-HABITAT. El derecho a una viviendaadecuada. Folleto informativo No 21/Rev.1. Disponível em: <www. http://www.ohchr.org/Documents/Publications/FS21_rev_1_Housing_sp.pdf.> Acesso em: 04 de junho de 2014.

OSORIO, Letícia Marques. O direito à moradia como direito humano. In: FERNANDES, Edésio; ALFONSIN, Betânia (Coord.). Direito à moradia adequada: o que é, para quem serve, como defender e efetivar. Belo Horizonte: Fórum, 2014. P. 39-68.

SAULE JÚNIOR, Nelson. Instrumentos de monitoramento do direito humano a moradia adequada. In: FERNANDES, Edésio; ALFONSIN, Betânia. Direito Urbanístico: estudos brasileiros e internacionais. Belo Horizonte: Del Rey, 2006. p. 215-250. 